IAC-04-IAF-I.1.10

\title{
INFLATABLE SPACE STRUCTURES TECHNOLOGY DEVELOPMENT FOR LARGE RADAR ANTENNAS
}

\author{
R. E. Freeland * \\ Richard G. Helms ${ }^{\dagger}$ \\ Paul B. Willis ${ }^{ \pm}$ \\ Jet Propulsion Laboratory, California Institute of Technology (USA) \\ Robert.E.Freeland@jpl.nasa.gov, Helms@jpl.nasa.gov, Paul.B.Willis@jpl.nasa.gov \\ M. M. Mikulas ${ }^{\S}$ \\ University of Colorado (USA), Mikulasmmm@aol.com \\ Wayne Stuckey ${ }^{£}$ \\ Gary Steckel ${ }^{\ddagger}$ \\ The Aerospace Corporation (USA) \\ Wayne.K.Stuckey@aero.org, Gary.L.Steckel@aero.org \\ Judith Watson • \\ NASA Langley Research Center (USA), Judith.J.Watson@ nasa.gov
}

\begin{abstract}
There has been recent interest in inflatable space-structures technology for possible applications on U.S. Department of Defense (DOD) missions because of the technology's potential for high mechanical-packaging efficiency, variable stowed geometry, and deployment reliability. In recent years, the DOD sponsored Large Radar Antenna (LRA) Program applied this new technology to a baseline concept: a rigidizable/inflatable (RI) perimeter-truss structure supporting a $\mathrm{mesh} / \mathrm{net}$ parabolic reflector antenna. The program addressed: (a) truss concept development, (b) rigidizable materials concepts assessment, (c) mesh/net concept selection and integration, and (d) developed potential mechanical-system performance estimates. Critical and enabling technologies were validated, most notably, the orbital radiation durable rigidized materials and the high modulus, inflatable-deployable truss members.

These results in conjunction with conclusions from previous mechanical-packaging studies by the U.S. Defense Advanced Research Projects Agency (DARPA) Special Program Office (SPO) were the impetus for the initiation of the DARPA/SPO Innovative Space-based Antenna Technology (ISAT) Program. The sponsor's baseline concept consisted of an inflatable-deployable truss structure for support of a large number of rigid, active radar panels. The program's goal was to determine the risk associated with the application of these new RI structures to the latest in radar technologies. The approach used to define the technology maturity level of critical structural elements was to: (a) develop truss concept baseline configuration(s), (b) assess specific inflatable-rigidizable materials technologies, and (c) estimate potential mechanical performance. The results of the structures portion of the program indicated there was high risk without the essential materials technology flight experiments, but only moderate risk if the appropriate on-orbit demonstrations were performed.
\end{abstract}

This paper covers both programs (LRA and ISAT) in two sections, Parts 1 and 2 respectively. Please note that the terms strut, tube, and column are all used interchangeably and refer to the basic strut element of a truss. Also, the paper contains a mix of English and metric dimensional descriptions that reflect prevailing technical discipline conventions and common usage.

\footnotetext{
*Principle Engineer, IAE and LRA Program Manager

† Senior A Engineer, ISAT Program Manager

${ }^{ \pm}$Member of Senior Tech. Staff, Structures and Materials Tech. Section

${ }^{\S}$ Professor Emeritus, Center for Aerospace Structures

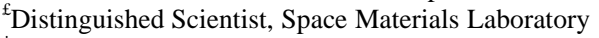

${ }^{\ddagger}$ Senior Scientist, Space Materials Laboratory

- Senior Researcher, Structures and Materials Competency Branch
} 


\section{LARGE RADAR ANTENNA TECHNOLOGY PROGRAM}

\section{Introduction}

The results of the NASA sponsored Inflatable Antenna Experiment (IAE) $)^{1-7}$ illuminated high potential mechanical performance in specific areas of serious interest to the DOD. Specifically, in the technology for mechanical-packaging efficiency, variable stowed geometry, deployment reliability, and low-cost hardware for very large reflector-antenna systems. For the DOD to establish the above technology advantages for a particular class of reflector-antenna systems, a technology assessment study was initiated. This study addressed the generation of estimates of potential mechanical performance for a reference reflectorantenna functional configuration definition. After considering a number of structural configurations, the sponsor selected a specific hybrid configuration design to develop. 8 .9 This new design was based on combining an inflatably deployed, orbitally rigidized perimeter support truss with a metallic mesh reflector that was contoured by a flexible net structure (see Figure 1).
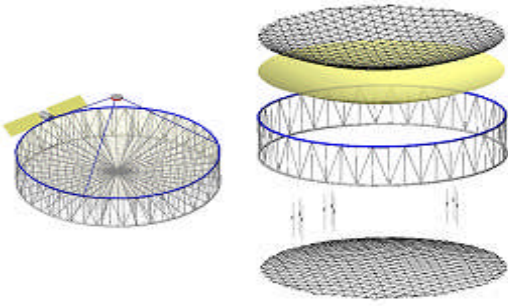

Net Mesh

Perimeter Truss

Tie Elements

Net

Fig. 1. LRA Baseline Configuration

Such a flexible system had great potential with all the associated cost savings from packaging a very large antenna structure into a reasonable size launch vehicle.

\section{Large Radar Antenna Program}

The Large Radar Antenna (LRA) Program was initiated to: (a) identify the critical, enabling technologies, (b) evaluate competing technology options, (c) select the most promising technologies for experimental characterization to the extent possible, (d) advance critical, enabling technology maturities to enable meaningful evaluations, and (e) generate estimates of potential mechanical performance, based on the program's technology database. The specific technical tasks emerging from program objectives included (a) functional mechanical performance requirements, (b) an antenna mechanical system configuration, (c) concepts for on-orbit rigidization of the flexible materials, (d) the development and application of analytical models to predict very large radar antenna on-orbit mechanical performance, and (e) the determination of scaling laws to facilitate the use of reduced scale test articles.

\section{Program Approach}

The LRA Program was unique in that it was the first attempt at applying a totally new and low maturity technology to a very large, high precision space structure. This was also done during a climate of low U.S. national technology resources. Available resources and expertise had to be identified and integrated with an approach that recognized the program's cost and schedule constraints. The resulting team consisted of the appropriate participants from JPL, the Aerospace Corp, Langley Research Center, University of Colorado Center for Space Construction, and L'Garde, Inc. This team collectively addressed the program objectives and implemented the technical tasks. The program flow diagram, Figure 2, delineates functional, technical, and institutional interactions.

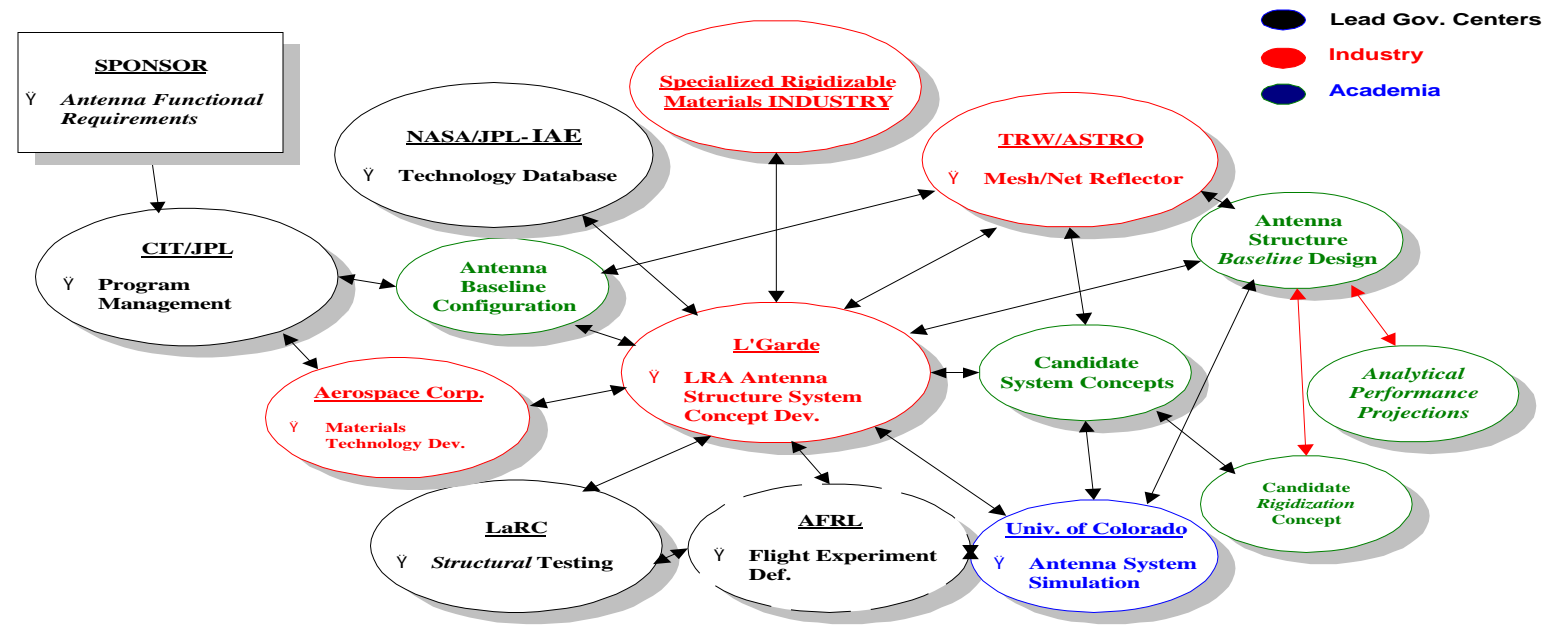

Fig. 2. Large Radar Antenna Program Flow Diagram 


\section{Program Implementation}

The program implementation was essentially the management of the separate technical tasks as executed by the LRA team members. Additionally, the team benefited significantly from consultation with other highly experienced experts from NASA, DOD, academia, and industry specializing in this new technology area. The integrated output from these tasks resulted in a successful assessment and advancement of the key and enabling technologies with identification of important supporting technologies.

\section{Functional Requirements}

The LRA functional requirements were derived from a variety of orbital mission concepts. As a consequence, requirements varied depending on the specific performance parameter. It should be noted that such parametric variations tended to converge in proportion to the increase in concept maturity, and the program's degrees of freedom. Mechanical functional requirement estimates are found in Figure 3.

\begin{tabular}{|l|l|}
\hline \multicolumn{2}{|c|}{ LARGE RADAR ANTENNA REQUIREMENTS } \\
\hline Aperture Diameter & Same as AIAT baseline \\
\hline Range of Orbits & Medium to high \\
\hline F/D (range) & 0.5 to 1 (baseline F/D $=.5)$ \\
\hline $\begin{array}{l}\text { Highest Operation RF } \\
\text { Frequency }\end{array}$ & $\mathrm{F}=$ same as AIAT \\
\hline Antenna Surface Precision & $\varepsilon=2.00 \mathrm{~mm}$ rms $(1.00 \mathrm{~mm}$ goal) \\
\hline Operational Lifetime & Five year requirement, ten year goal \\
\hline $\begin{array}{l}\text { Materials Outgassing Req. } \\
\text { (min.) Levels }\end{array}$ & $<1 \%$ TML, 0.1\% CVCM $>$ \\
\hline Maximum Slewing Rates/Range & $\begin{array}{l}\text { Angular acceleration about three axis } \\
\text { of: TBD }<\alpha<\text { TBD }\end{array}$ \\
\hline Deployed Max. Acceleration & $\pm 0.005 \mathrm{~g}$ \\
\hline ESD/Constraints & $\begin{array}{l}\text { Each Cond. layer of MLI shall be } \\
\text { grounded }\end{array}$ \\
\hline
\end{tabular}

Fig. 3. LRA Functional Requirements

\section{LRA Structural System Configuration}

\section{Development}

The mechanical system configuration definition was based on a number of requirements and considerations that included the: (a) sponsor selected hybrid structural system concept, (b) LRA RF geometric design, (c) functional LRA system mechanical performance requirements, (d) selection and integration of a concept for the mesh/net reflector structure, (e) anticipated truss tube orbitally rigidized materials stiffness characteristics, and (f) loading imposed on the perimeter truss resulting from the tension field in the mesh net structure. The starting point for the reflector structure was the LRA baseline RI truss antenna configuration integrated with the previously developed and successfully flown Astro Aerospace Corp. AstroMesh Reflector. ${ }^{10}$

The LRA baseline truss concept was developed by L'Garde, Inc., which had recently innovated, designed, manufactured, and flown the IAE for JPL. The University of Colorado Center for Space Construction assisted L'Garde with critical performance analysis of the new baseline design.
More to the point, the LRA baseline antenna configuration needed an optimized perimeter truss with low mass and high stowed package efficiency. Various truss types were characterized including the: (a) standard, (b) two-story, (c) prestressed, (d) offset, (e) Warren, and (f) diamond truss (with diameter variations between the top and bottom "longeron ring"). See Figure 4.

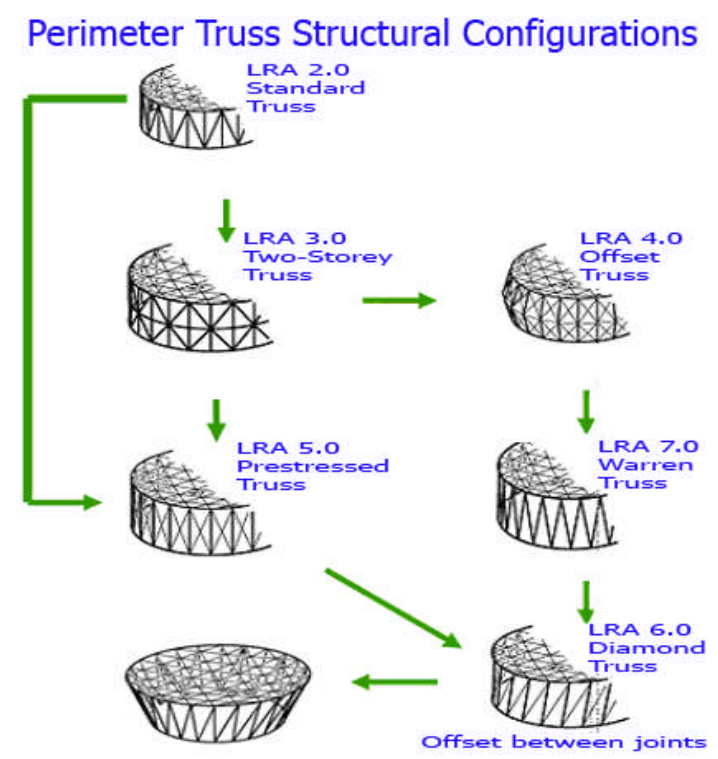

Fig. 4. LRA Truss Structure Concepts

The AstroMesh's utilization of two "back-to-back" mesh/net structures interconnected with multiple ties was the starting point for the LRA baseline mesh reflector. The primary structures difference between the baseline and the AstroMesh antenna was that the latter used an all-mechanical perimeter support truss.

A significant enhancement to the baseline perimeter truss was the Tension Drum ${ }^{11}$ innovation developed by the University of Colorado in conjunction with L'Garde, Inc., Figure 5. The Tension Drum structurally decoupled the mesh/net from the Rigidizable Inflatable (RI) perimeter truss with respect to the geometric precision of the truss mounting points, and the required truss stiffness. This was accomplished by introducing an additional truss structure interior to the perimeter truss. This "tension" truss acted as a transition structure to ameliorate the need for high RI perimeter truss dimensional tolerances and stiffnesses. It contributed to higher mesh reflector precision and reduced RI stiffness requirements to be commensurate with a natural frequency on the order of $0.05 \mathrm{~Hz}$.

This mechanical system configuration study resulted in a downselect to the Tension Drum concept in combination with the standard truss configuration. This hybrid design met the aforementioned requirements of optimized mass and packaging efficiency. 

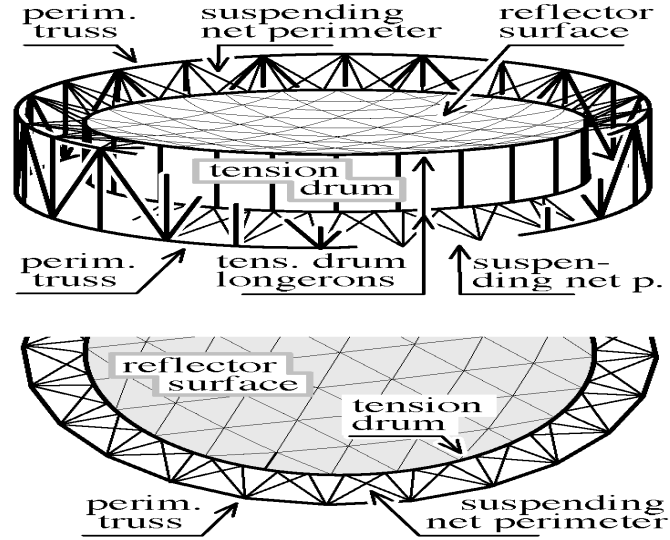

Fig. 5. Open Ring and Tension-Drum Concepts

\section{Rigidizable Materials Concepts Evaluation}

This task addressed the technology maturity level and orbital rigidization applicability of specific flexible materials concepts to the LRA structural system. This was accomplished by (a) identification of existing concepts, (b) evaluation of existing but very limited property databases, (c) selection of high potential concepts, (d) experimental characterization of these concepts, and (e) technology advancement of high potential concepts to enable meaningful assessment.

The materials rigidization task began with the determination of criteria for the comparative evaluation of truss tube rigidization concepts, Figure 6. These criteria were developed by the LRA team and applied to an available technology database that was compiled from various programs between 1987 and 1999. The results of this process identified two basic classes of materials concepts as the most promising to warrant their continued investigation. These composite materials concepts included (a) Sub$\mathrm{T}_{\mathrm{g}}$ rigidizable/thermoplastics and elastomerics, and (b) UV and heat cured thermoset plastics. The aforementioned technology database, as it applied to each of these concepts, was then used as the starting point for developing more realistic estimates of potential performance (see summary, Figure 7).

The technology advancements were based on: (a) experimental materials characterization at the coupon level, (b) tailored truss strut tube laminate designs, (c) implementation of specialized fabrication techniques, and (d) extensive functional and mechanical truss strut performance tests (see Figure 8, which represents only about $10 \%$ of the test matrix). This test matrix, used for each concept, identified all tests, hardware, responsible organizations, and schedule.

\begin{tabular}{|l|c|}
\hline \multicolumn{1}{|c|}{ Evaluation Criteria } & $\begin{array}{c}\text { Importance } \\
\text { Rating } \\
(\mathbf{0}-\mathbf{1 . 0})\end{array}$ \\
\hline Mechanical properties & 1.0 \\
\hline $\begin{array}{l}\text { Strut accuracy and precision } \\
\text { (repeatability) }\end{array}$ & 1.0 \\
\hline Packaging efficiency & 1.0 \\
\hline Resistance to space environment & 1.0 \\
\hline Truss weight & 0.9 \\
\hline Implementation complexity & 0.9 \\
\hline Ground testability & 0.9 \\
\hline Reliability and simplicity & 0.9 \\
\hline Thermal stability (CTE, shrinkage) & 0.9 \\
\hline $\begin{array}{l}\text { Outgassing before, during, } \\
\text { and after rigidization }\end{array}$ & 0.8 \\
\hline $\begin{array}{l}\text { Repeatability and precision of } \\
\text { deployment }\end{array}$ & 0.8 \\
\hline Stowage and shelf-life limitation & 0.7 \\
\hline Positive rigidization control & 0.7 \\
\hline
\end{tabular}

Fig. 6. Evaluating Rigidizing Technique

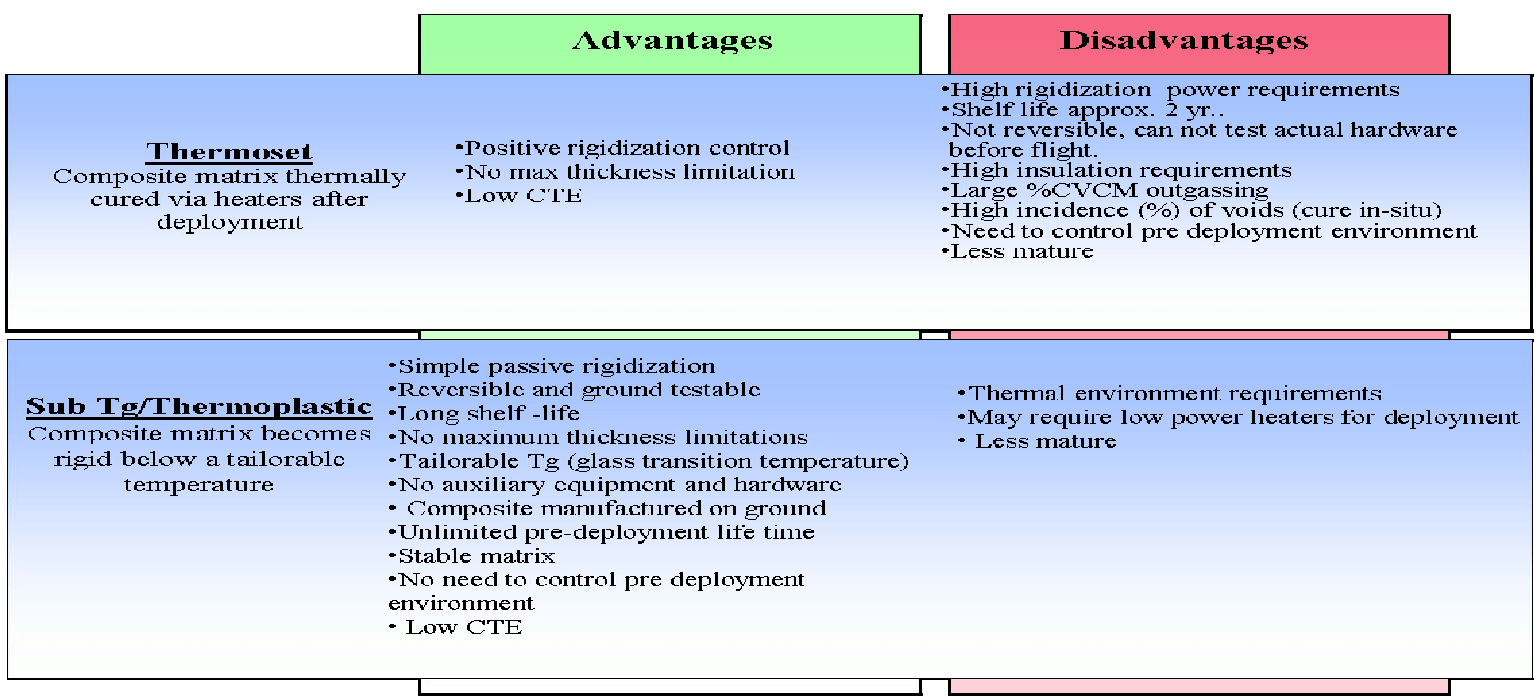

Fig. 7. LRA Rigidization Materials Tradeoffs 


\begin{tabular}{|c|c|c|c|}
\hline TEST & Sub-Tg & Sub-Tg & Thermoset \\
\hline & (Urethane-based) & [Epoxy-based] & [3 Candidates] \\
\hline \multicolumn{4}{|l|}{ Modulus of Tubes } \\
\hline Test Method & Vibration & Vibration & Vibration \\
\hline Sample Required & Tube & Tube & Tube \\
\hline Sample Size & $36^{\prime \prime}(\mathrm{L}) \times 4^{\prime \prime}(\mathrm{D}) \times 0.012^{\prime \prime}(\mathrm{T})$ & $36 "(L) \times 4 "(D) \times 0.012 "(T)$ & $36^{\prime \prime}(\mathrm{L}) \times 4 "(\mathrm{D}) \times 0.012^{\prime \prime}(\mathrm{T})$ \\
\hline Sample C andition & $D, E$ & $\mathrm{D}, \mathrm{F}$ & B.D \\
\hline Nof Samples & 3 & 3 & 3 \\
\hline Facility & NASA Langle $y$ & NASA Langle $Y$ & NASA Langle $Y$ \\
\hline Contact Person & Judith Watson & Judith Watson & Judith Watson \\
\hline Phone Number & $(757) 864-3116$ & $(757) 864-3116$ & $(757) 864-3116$ \\
\hline Start Date & TBD & TBD & Oct. 15.1999 \\
\hline End $D$ ate & TBD & TBD & TBD \\
\hline Temperature Range & TBD & TBD & TBD \\
\hline \multicolumn{4}{|c|}{ Modulus \& Poisson's Ratio } \\
\hline \multicolumn{4}{|c|}{ of flat coupons, E1,E 2, N u } \\
\hline Test Method & DMA & DMA & DMA \\
\hline Sample Required & Flat coup on & Flat coupon & Flat coupon \\
\hline Sample Size & $6^{\prime \prime} \times 6^{\prime \prime}$ & $6^{\prime \prime} \times 6^{\prime \prime}$ & $6^{\prime \prime} \times 6^{\prime \prime}$ \\
\hline Sample Condition & E & $\mathrm{F}$ & A,B \\
\hline Nof Samples & 1 & 1 & 1 \\
\hline Facility & Aerospace & Aerospace & Aerospace \\
\hline Contact Person & Wayne Stuckey & Wayne Stuckey & Wayne Stuckey \\
\hline Phone Number & $(310) 336-7389$ & (310) $336-7389$ & $(310) 336-7389$ \\
\hline Start Date & TBD & TBD & Sept. 30.1999 \\
\hline End $D$ ate & TBD & TBD & TBD \\
\hline Temperature $\mathrm{R}$ ange & TBD & TBD & TBD \\
\hline
\end{tabular}

Fig. 8. Test Matrix for the Large Radar Antenna (Example)

The test matrix illuminates the large number of necessary characterizations. However, in terms of the risk of using this new technology, there were two key and critical issues that had essentially no meaningful database at the initiation of the program. These issues were the (a) orbital radiation durability of rigidized flexible materials and (b) feasibility of achieving high modulus rigidized truss tubes on-orbit. They were the most significant challenges to the LRA Program.

Characterizing and validating space radiation durability of rigidized flexible materials were accomplished through accelerated radiation testing ${ }^{12}$ at the coupon level. Samples of all the materials under evaluation were exposed to doses of simulated geosynchronous orbital radiation equivalent to 10 years of exposure. Coupons were periodically removed and tested for modulus, glasstransition-temperature, outgassing, and surface degradation in intervals equivalent to 2 to 3 years of onorbit exposure. Testing was done at Aerospace Corporation arranged in sample/chamber configurations as illustrated by Figure 9 .

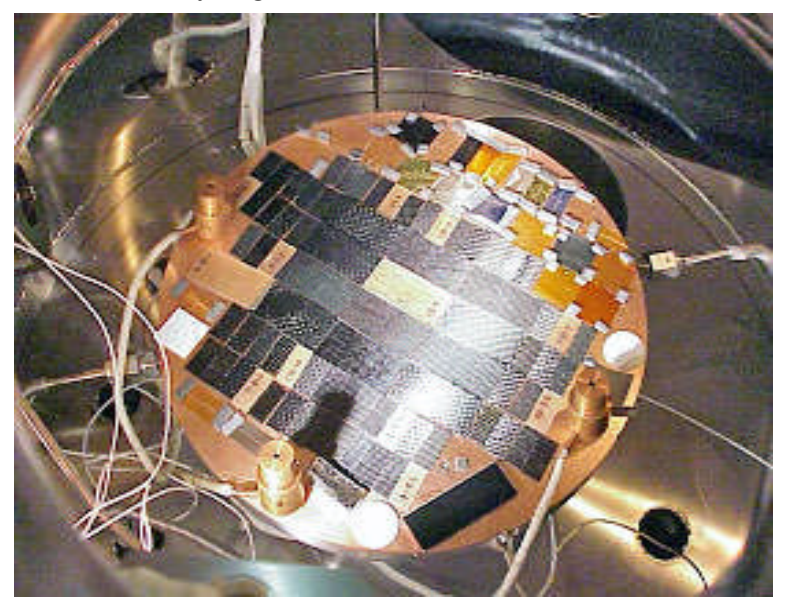

Fig. 9. LRA Samples in Radiation Test Chamber
Test results ${ }^{12}$ indicate that a number of exposed materials show surprising durability in their response to the radiation environment. Outgassing was an issue for some resins, and would result in property changes in some of the sub- $\mathrm{T}_{\mathrm{g}}$ resins. Figure 10 is a generic plot of radiation effects data for some of the composite systems evaluated for the LRA Program. Experimental results clearly indicate the radiation stability of this class of materials for space applications.

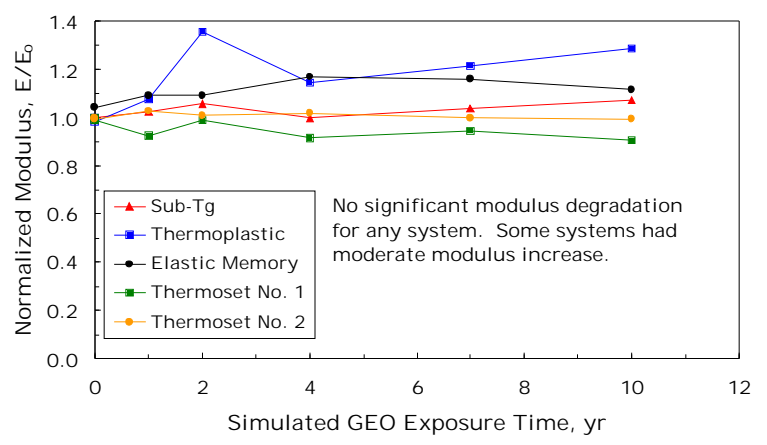

Fig. 10. Materials Properties as a Function of Radiation Dosage

The potential of this new technology for achieving high modulus truss members on-orbit was further addressed by the development of realistically sized test hardware and mechanical laboratory characterization. The detailed designs of the truss strut elements were a function of (a) the specific rigidization concept, (b) loading and stiffness requirements, and (c) fabrication techniques capability. A minimum statistical test set of three strut samples was used. Four-inch (full-scale) diameter and 1-m (scaled) length tubes, were tested as representative of full-sized truss bays. Strut testing was performed at the NASA Langley Research Center using a new and one-of-a-kind RI tube mechanical test facility. All the truss test articles were developed and fabricated by L'Garde, Inc., with the exception of two struts constructed at ILC Dover. 
The bending moduli were determined using static and dynamic cantilever techniques. Axial moduli were evaluated using customized tension/compression testing techniques, Figure 11.

Modulus test results (Figure 12) exceeded the minimum required capability of 3 MSI for both rigidization concepts. Variations in the moduli of the eleven test specimens were not too surprising when one considered that during the manufacturing period: (a) tube designs were modified and changed, (b) fabrication processes improved, and (c) experimental materials quality was refined rapidly. Regardless of these moduli variations, "feasibility" was demonstrated for these RI tube technologies.

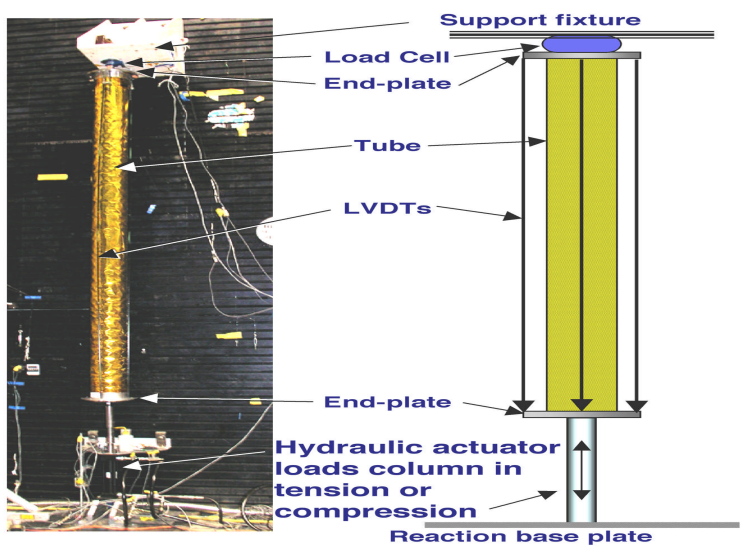

Fig. 11. Typical Mechanical Axial Test Setup

\begin{tabular}{|c|c|c|c|c|c|c|c|}
\hline $\begin{array}{l}\text { Column } \\
\text { No }\end{array}$ & Length, in & Diameter, in & $\begin{array}{c}\text { Thickness, } \\
\text { in }\end{array}$ & $\begin{array}{c}\text { Axial Tension } \\
{\mathrm{lb} / \mathbf{i n}^{2} \mathrm{E}+06}^{2}\end{array}$ & $\begin{array}{c}\text { Axial } \\
\text { Compression } \\
\text { lb/in } 2 \text { E+06 } \\
\end{array}$ & $\begin{array}{c}\text { Bending, } \\
\text { Static } \\
\text { lb/in }{ }^{2} \text { E+06 } \\
\end{array}$ & $\begin{array}{c}\text { Bending, } \\
\text { dynamic } \\
\text { lb/in }{ }^{2} \text { E+06 } \\
\end{array}$ \\
\hline 1 & 31.37 & 4.07 & .0138 & 4.88 & 4.90 & 4.25 & 4.75 \\
\hline 2 & 31.37 & 4.07 & .0138 & 4.81 & 4.76 & 4.09 & 4.76 \\
\hline 3 & 36.37 & 4.07 & .0138 & 4.84 & 4.78 & 4.27 & 4.07 \\
\hline 4 & 34.81 & 4.06 & .0123 & 5.33 & 5.23 & 4.87 & 5.22 \\
\hline 5 & 36.62 & 4.06 & .0123 & 5.61 & 5.56 & 5.01 & 5.47 \\
\hline 6 & 36.50 & 4.06 & .0123 & 5.55 & 5.43 & 4.81 & 5.46 \\
\hline 7 & 38.12 & 4.04 & .0142 & 5.86 & 5.81 & 5.31 & 5.92 \\
\hline 8 & 38.12 & 4.04 & .0142 & 5.93 & 5.92 & 5.36 & 6.04 \\
\hline 9 & 36.32 & 3.68 & .0138 & 13.55 & 12.82 & 10.50 & 12.98 \\
\hline 10 & 36.25 & 3.67 & .0138 & 13.82 & 13.44 & 9.35 & 13.13 \\
\hline 11 & 36.25 & 3.68 & .0138 & 12.94 & 13.18 & 9.80 & 12.51 \\
\hline
\end{tabular}

Fig. 12. Typical Strut Mechanical Results (msi)

\section{LRA Summary}

The results of this research program showed that new RI structures technologies had real potential for meeting all the LRA mission mechanical requirements. The maturity level of the critical and enabling technologies, however, still required significant advancements.

The two-year plus LRA Program resulted in a number of meaningful developments including (a) experimental characterization of promising concepts for the RI flexible materials, (b) development of an optimal perimeter truss concept that emerged from the seven candidates, (c) potential mechanical performance estimates for a very large hybrid reflector antenna structure, and (d) definition of an effective mechanical interface between an inflatable truss and a flexible mesh-net reflector system.

The most significant developments - major inflatable structures technology advancements - were validated space-radiation durable rigidizable materials, and the high modulus of RI truss structure elements.

In summary, the program's significant results were recognized by DARPA and were contributory to the initiation of the ISAT Program.
INNOVATIVE SPACE-BASED RADAR ANTENNA TECHNOLOGY PROGRAM

\section{Introduction}

DARPA's recent pursuit of structures technologies to enable a new class of very large, active planar radar antennas had illuminated the need for deployable structures with very high mechanical-packaging efficiencies and variable stowed geometries. Previous DARPA RI technology studies combined with the LRA results were contributory to the creation of the Innovative Space-based Radar Antenna Technology Program (ISAT).

The ISAT Program RI structures tasks were established to determine the risk associated with applying this new, low maturity technology to DARPA's baseline radar-antenna concept, Figure 1. The large aperture of the RF planar array antenna hundreds of meters long and a few meters wide strongly suggested a truss type backup structure. With its numerous repeating bays, the concept lent itself well to using RI packaging technologies to minimize payload volumes and launch vehicle costs. 


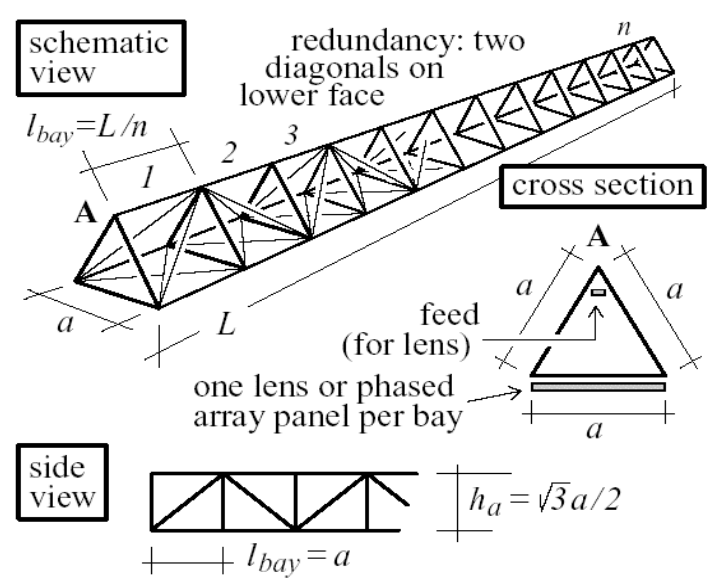

Fig. 1 ISAT Baseline Configuration Design

\section{The ISAT Program}

The ISAT Program was a risk assessment activity designed to establish the viability of applying Rigidizable Inflatable (RI) technologies to a structure supporting a large number of rigid, radar panels. The ISAT Program addressed (a) generating system mechanical requirements, (b) developing generic inflatable deployable truss configuration designs, (c) advancing the technology database for concepts for the rigidization of flexible materials, and (d) projecting onorbit mechanical performance. The program was intended to incrementally advance previously selected RI technologies to the degree required to enable such an assessment. Specific truss concepts were developed and analytically evaluated using generated statistical mechanical test data from full-scale RI structural elements. The constitutive mechanical behavior was characterized empirically and phenomenologically. This intrinsic mechanical behavior was then incorporated into high-fidelity structural models to simulate the radar-antenna performance. Overall program assessment was based on technology potential regarding system requirements and current maturity levels.

To meet program objectives, program technical tasks were grouped into categories addressing: (a) trussstructure concept definitions, (b) rigidizable-materials concepts, and (c) structural performance simulation.

\section{Program Approach}

The risk-assessment approach was so synergistic to the LRA application feasibility study that the same LRA technical team, with a few additions, was used for ISAT (see LRA Figure 2). The team was responsible for all aspects of implementing the structures program.

The most significant change was the structures system concept development performed by the government team in contrast to the LRA functional organization. Another important change in approach was that two manufacturers participated in the program for design, manufacture and RI structural elements optimization (L'Garde, Inc. and ILC Dover, Inc.).

\begin{tabular}{|l|}
\hline \multicolumn{1}{|c|}{ Guidelines } \\
\hline $\begin{array}{l}\text { Free-free frequency }(\mathrm{f}=0.05 \mathrm{~Hz}, \mathrm{~T}=20 \text { secs. }) \\
\text { Assumption: All mass distributed along beam }\end{array}$ \\
\hline Strut buckling due to boost load $(\mathrm{g}=0.001)$ \\
\hline Strut slenderness ratio $(\mathrm{L} / \mathrm{d}<=100)$ \\
\hline Thermal stability (CTE, shrinkage) \\
\hline Stowage volume \\
\hline Controlled deployment \\
\hline $\begin{array}{c}\text { Dimensional stability } \\
\text { Fig. 2. ISAT Primary Truss Antenna Structural } \\
\text { Guidelines }\end{array}$
\end{tabular}

There were a number of different approaches for determining the risk associated with the application of a relatively new technology to a specific and challenging class of antenna structures. This assessment required the selection of an approach/technique that could be implemented with the LRA/ISAT inflatable structures technology database and, at the same time, was familiar and acceptable to the program sponsor. A well known, frequently used codification that addressed technology maturity definitions was NASA's Technology Readiness Level (TRL) system that is based on fairly simplified narrative descriptions of each technology level ${ }^{13}$. Potential ISAT risk was driven by (1) the inflatablerigidizable materials concepts maturity, (2) trussstructural system definition, (3) risk associated with advancing enabling/supporting technologies to point of flight, and (4) how well projected performance met mechanical/structural system requirements. As such, applying the NASA TRL system to ISAT seemed appropriate and straightforward.

Since the database in each technology area addressed by the ISAT program came directly from the specific program technical tasks and their integrated results, a modular format was selected for the task definitions and result summaries. The individual, technical tasks managed by the technology experts directly correlated with the TRL system rationale. Primarily, task results, along with technology databases from related DOD, NASA, and other relevant programs, determined ISAT structural technology element maturities. Technologies were separated into three areas: (a) critical and enabling, (b) secondary (supporting), and (c) groundbased (supporting).

\section{Program Technical Tasks}

Technical tasks were formulated and organized such that their integral results satisfied the overall program objectives. A recognized authority in their respective technology areas managed each technical task. Extensive interaction between the tasks was necessary for the effective dissemination and utilization of task results. The task descriptions and their activities are briefly summarized below. There were three generic technology areas consisting of several sub-elements. 


\section{A. Truss Structure Concept Definition}

This task addressed the development and evaluation of candidate support truss concept definitions for the purpose of structural optimization. The design guidelines (Figure 2) and/or considerations were the basis for developing an optimized ISAT antenna truss structure design.

Basic design considerations included (a) structural stiffness for robust control, (b) antenna and truss tube length to diameter ratios to optimize antenna stiffness, (c) structural mass, (d) mechanical packaging, (e) trusstube mechanical design properties, (f) truss loading, and $(\mathrm{g})$ orbitally induced deformations. Parametric trades included (a) longeron diameter as a function of bay size, (b) truss weight as a function of bay size, (c) antenna modal frequency variation due to mass and its distribution, and (d) thermal stability of truss design. Figure 3 represents the optimized antenna structure design generated from parametric studies using the above considerations. Figure 4 is an example of such parametric study results.

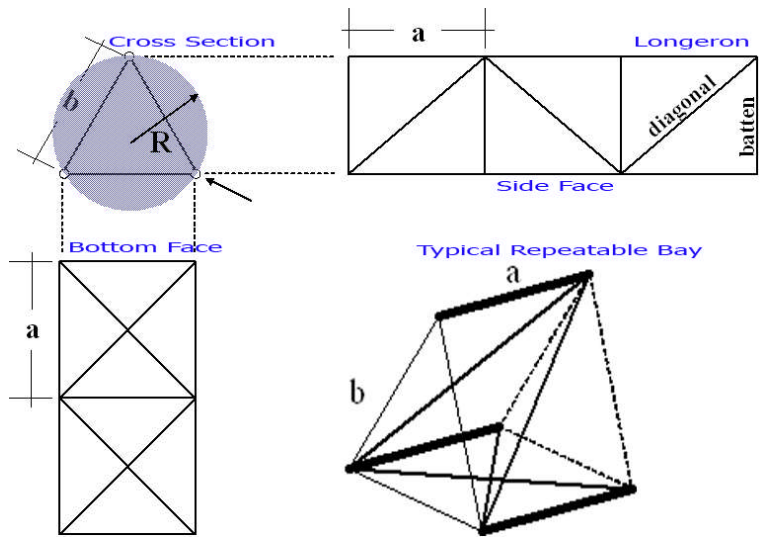

Fig. 3. ISAT Truss Definitions

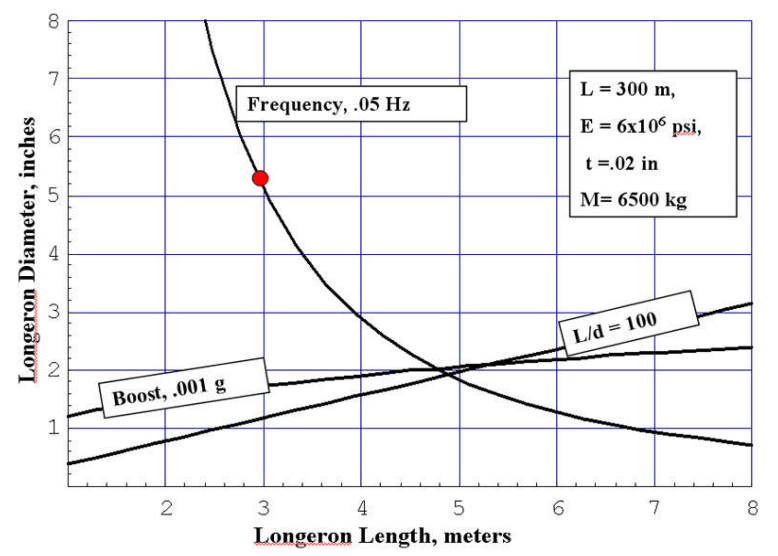

Fig. 4. Longeron Diameter vs. Bay Size

\section{Rigidizable Materials Concepts Evaluation}

This task addressed the determination and experimental verification of the technology maturity levels of specific concepts for the orbital rigidization of flexible materials. Structural analysis and design for the ISAT optimized truss structure addressed very large truss structural behavior, detailed structural design of truss tubes, and buckling issues for orthotropic composite truss members. Such analysis was fundamental to the design of a large truss using inflatable/rigidizable structural elements. Two basic structural element concepts were evaluated in the program: the Isogrid woven tube from ILC Dover, Inc., and a more conventional, thin-walled cylinder by L'Garde, Inc. The Isogrid construction is shown here as an example, Figure 5.

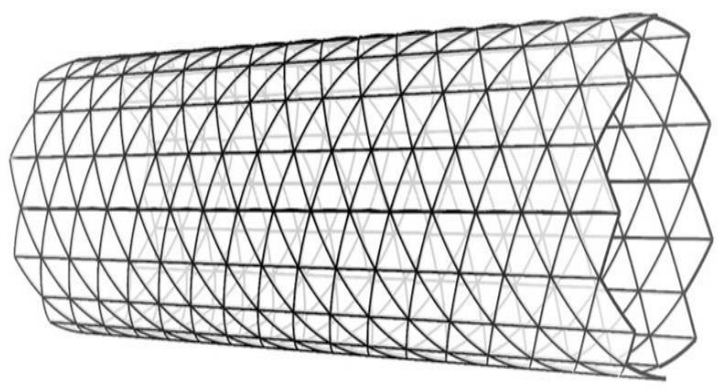

Fig. 5. ISAT Isogrid Truss Tube Configuration

Specific issues addressed included Isogrid truss tube grid spacing (Figure 6), local composite tube wall buckling where mass was minimized as a function of loading, and the structural and thermal behavior of very large truss structures. This also included the estimated structural-element manufacturing imperfections effects. The design optimizations made at L'Garde, Inc. for its monocoque tube concepts were also thoroughly investigated with similar trades and detailed designs.

Both the ILC Dover and L'Garde tube designs proved to be adequate for their respective ISAT antenna truss mechanical design requirements.

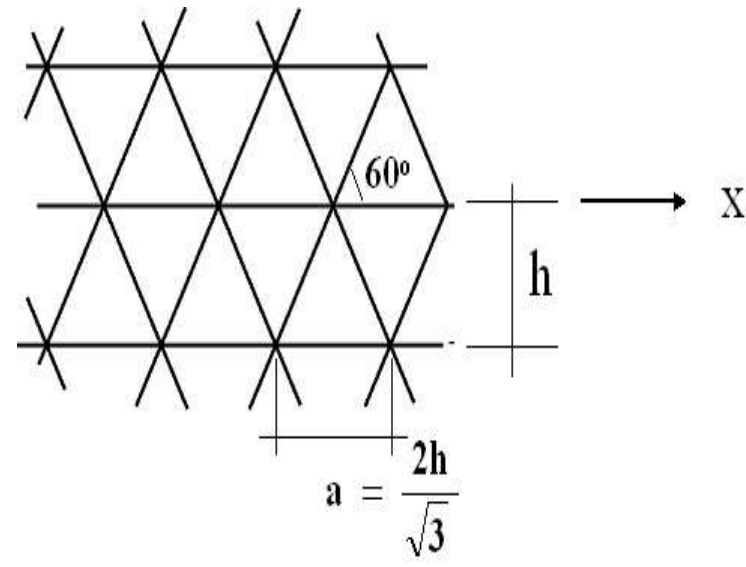

Fig. 6. Micro-Mechanical Analysis for Effective Isogrid Properties

Micro-Mechanical Analysis

In this composite truss development exercise, the tubes were qualified by requiring that their major fiber controlled properties agree with those predicted from micromechanics. This ensured the predictability and repeatability of the primary mechanical properties including all moduli and coefficients of thermal expansions which control the truss-structure dimensional accuracy. An example is shown in Figure 7 of how well micromechanics can predict a wellconsolidated composite laminate's properties. 


\begin{tabular}{|l|l|l|}
\hline \multicolumn{3}{|c|}{ KEVLAR LAMINATE } \\
\hline Property & Dupont Tests & $\begin{array}{l}\text { Micro- } \\
\text { mechanics }\end{array}$ \\
\hline Axial Modulus & $11 \times 10^{6} \mathrm{psi}$ & 11.04 \\
\hline Transv. Modulus & $0.8 \times 10^{6} \mathrm{psi}$ & .79 \\
\hline Shear Modulus & $0.3 \times 10^{6} \mathrm{psi}$ & .309 \\
\hline Poison's ratio & .34 & .336 \\
\hline C.T.E. & $-2.2 \times 10^{-6} \mathrm{in} / \mathrm{in} /{ }^{\circ} \mathrm{F}$ & -2.08 \\
\hline C.T.E., Trans. & $32 \times 10^{-6} \mathrm{in} / \mathrm{in} /{ }^{\circ} \mathrm{F}$ & 37 \\
\hline Density & $0.049 \mathrm{lb} / \mathrm{in}^{3}$ & .049 \\
\hline
\end{tabular}

Fig. 7. Example of Micromechanics Accuracy in Predicting Lamina Properties

In most cases the fabricated tube properties could be predicted from micromechanical analysis by using the proper resin/fiber volume fraction. The typical difference between test and analysis was about 10 to $20 \%$. Further quality control of volume fraction would likely improve that correlation.

Column Design, Manufacturing and Database This task addressed integrating the truss longeron detailed mechanical design data with the associated manufacturing process to develop the technology databases. A particularly important aspect of this database was the statistical experimental mechanical characterizations of realistically sized structural elements. The purpose of the database was to capture and archive design details, materials properties, test results, and to highlight the manufacturing processes used for the inflatable structures investigated. This database serves as a source of information for constitutive analysis, micro-mechanics modeling, statistical mechanical analysis of column properties, and manufacturing reproducibility. More specifically, the subject technology databases were formatted to enable (a) easy access for archival review, (b) illumination of composite-materials properties from micromechanics analysis for correlation with

\begin{tabular}{|l|l|}
\hline \multicolumn{1}{|c|}{ Test } & \multicolumn{1}{c|}{ Comments / Test Variables } \\
\hline Tensile Modulus & Ambient and max. and min. service temps; assess effect of folds \\
\hline Tensile Strength & Ambient temperature; Assess effect of folds \\
\hline Flexural Modulus & Determine temp. dependence; relates to deployment temp., max. service temp., \& tube bending \\
\hline Flexural Creep & Measure at maximum service temperature \\
\hline Fiber Content & Estimate by image analysis; determine variability between prepreg lots \\
\hline Optical Microscopy & Fiber / matrix distribution; void content, folding damage, seams on tubes \\
\hline Matrix T $\mathrm{g}$ & Deter. deployment temp. exposure \& outgassing effects; comp. composite matrix $\mathrm{T}_{\mathrm{g}}$ w/ neat resin $\mathrm{T}_{\mathrm{g}}$ \\
\hline Damping & DMA tan vs temp. and frequency \\
\hline Outgassing & Compare to flight requirements; effective of pre-launch bake-out \\
\hline Panel CTE & Compare with tubes fabricated from same prepreg lots \\
\hline Tube CTE & Laser interferometer; effects of thermal cycling and folds \\
\hline
\end{tabular}

Fig. 8. Constitutive Materials Characterization Goals constitutive behavior, (c) manufacturing approaches for subsequent development, and (d) structural test results to determine capabilities for this new class of space structures. This database was unique with respect to this new class of space structures. It statistically addressed materials characteristics from the coupon to the structural element level maintaining their pedigree and histories. Hygrothermal behavior, the parametrics associated with fabrication, and hardware dimensional variations were also included.

\section{Materials Technology Assessment}

To understand the basic constitutive (real-life) nature of these RI materials technologies, a testing program was undertaken by team members at Aerospace Corporation to closely measure material mechanical and thermomechanical properties in the appropriate space environment. $^{14-16}$

This self-consistent dataset served several purposes: (a) materials property data required for the analytical models of the space-structure mechanical performance, (b) verification of the accuracy of inputs used in the predictive models, and (c) meeting materials design requirements. The data was also used to help understand NASA Langley Research Center (LaRC) tube measurements, which should correlate with the laboratory sample measurements. Additional data not obtained in the LaRC tests could be obtained in laboratory measurements, e.g., damping and temperature-dependent properties.

For the materials being considered, understanding the property temperature dependence was critical to their successful use. Aerospace Corporation laboratories measured a variety of temperature-dependent properties. Coupon sample measurements were a straightforward means to monitor any material property changes that may occur during manufacturing, aging, or storage. Figure 8 represents a summary of materials test goals, and Figures 9, 10, and 11 are examples of important test results. 
Folding and deployment (Figure 9) had very little effect on sub- $\mathrm{T}_{\mathrm{g}}$ rigidizable tube CTE (slope of thermal strain/temperature curve). Although CTE was higher than anticipated, coupon testing demonstrated that predicted CTE was achieved with enhanced processing measures improving control resin content control.

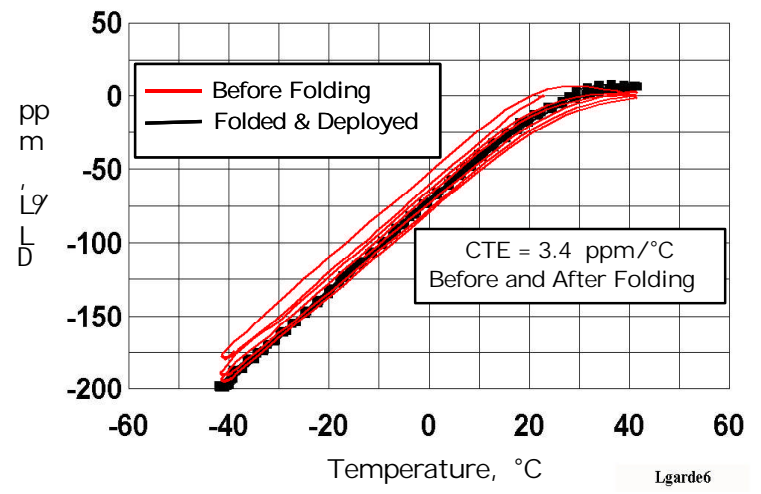

Fig. 9. Effect of Folding on Tube Axial CTE

ISAT tube CTE was very sensitive (Fig. 10) to the composite fiber content (percent by volume) over a wide temperature range. As may be expected, the higher the fiber volume, the lower composite tube CTE.

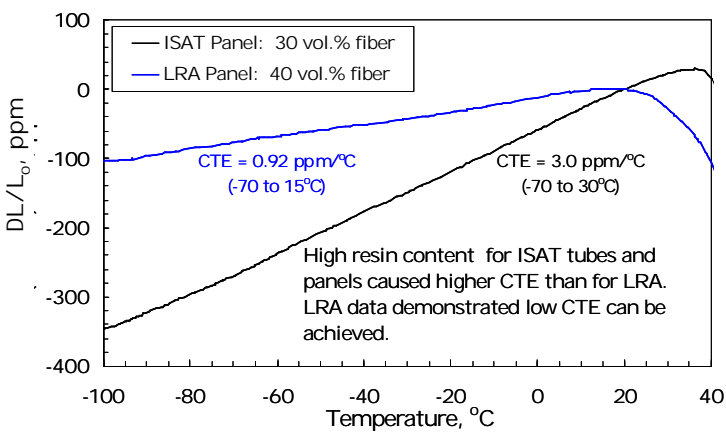

Fig. 10. CTE Coupon Tests for LRA and ISAT Sub-T $\mathrm{T}_{\mathrm{g}}$ Composites

Figure 11 demonstrates that sub- $\mathrm{T}_{\mathrm{g}}$ and thermoplastic rigidizable composites had very stable elastic moduli that were insensitive to ISAT operational temperature changes, but which decreased very rapidly at higher temperatures to readily allow stowing and deployment with minimal damage.

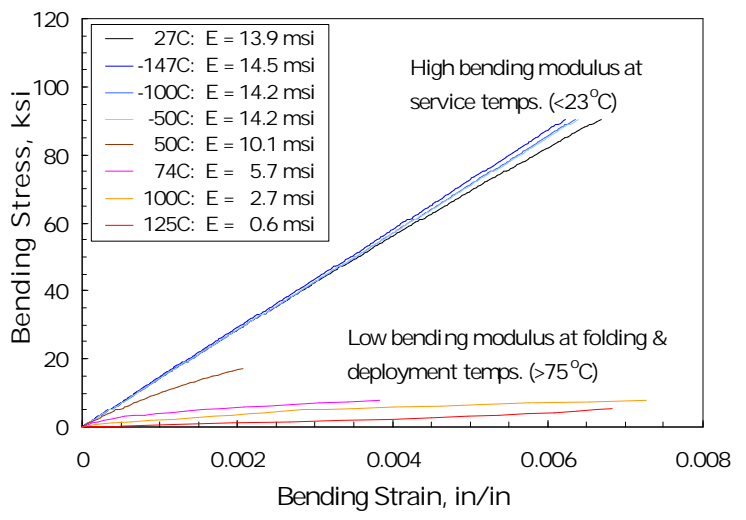

Fig. 11. Bending Stress-Strain Curves for ISAT Coupon Samples
Truss Tube Experimental Characterization

Langley Research Center's ISAT Program objective was to experimentally evaluate rigidized tube structural post-deployed properties as related to their applicability to the ISAT radar truss. Figure 12 is a strut test-matrix summary. Specific characteristics evaluated were stiffness, member strength, tube length change after mechanical packaging, deployment, and rigidization.

\begin{tabular}{|c|c|c|}
\hline Performance Evaluation & $\begin{array}{c}\text { 3-m } \\
\text { columns }\end{array}$ & $\begin{array}{c}\text { 5-m } \\
\text { columns }\end{array}$ \\
\hline $\begin{array}{l}\text { Thermoset and } \\
\text { thermoplastic material } \\
\text { systems }\end{array}$ & $\mathbf{X}$ & $\mathbf{X}$ \\
\hline $\begin{array}{l}\text { Length measurements pre- } \\
\text { and post- folding }\end{array}$ & $\mathbf{X}$ & $\mathbf{X}$ \\
\hline $\begin{array}{l}\text { Post packaging and } \\
\text { deployment performance } \\
\text { evaluation }\end{array}$ & $\begin{array}{l}----- \\
\end{array}$ & ------ \\
\hline \multicolumn{3}{|l|}{ Room temperature testing } \\
\hline Axial tension stiffness & $\mathbf{X}$ & $\mathbf{X}$ \\
\hline $\begin{array}{l}\text { Axial compression } \\
\text { stiffness }\end{array}$ & $\mathbf{X}$ & $\mathbf{X}$ \\
\hline $\begin{array}{l}\text { Pure-moment bending } \\
\text { stiffness }\end{array}$ & $\mathbf{X}$ & $\mathbf{X}$ \\
\hline $\begin{array}{l}\text { Axial compression } \\
\text { failure }\end{array}$ & $\mathrm{X}$ & $\mathbf{X}$ \\
\hline \multicolumn{3}{|l|}{$\begin{array}{l}\text { Reduced temperature } \\
(-50 \text { C) testing }\end{array}$} \\
\hline Axial tension stiffness & $\mathbf{X}$ & $\mathbf{X}$ \\
\hline $\begin{array}{l}\text { Axial compression } \\
\text { stiffness }\end{array}$ & $\mathbf{X}$ & $\mathbf{X}$ \\
\hline $\begin{array}{l}\text { Pure-moment bending } \\
\text { stiffness }\end{array}$ & $\mathbf{X}$ & $\mathbf{X}$ \\
\hline $\begin{array}{l}\text { Axial compression } \\
\text { failure }\end{array}$ & $\mathbf{X}$ & $\mathbf{X}$ \\
\hline $\begin{array}{l}\text { Qualitative assessment of } \\
\text { column deployed } \\
\text { configuration }\end{array}$ & $\mathbf{X}$ & $\mathbf{X}$ \\
\hline
\end{tabular}

Fig. 12. Strut Test Matrix Summary

Tube test elements underwent axial and bending tests. For statistical relevance, seven $3 \mathrm{~m}$ tubes and three $5 \mathrm{~m}$ tubes were tested at room temperature. Additional tubes were tested at lower temperatures to simulate cold operational environment effects. Results showed that, after a small number of mechanical packaging and deployment cycles of the rigidizable tubes, there were only minor changes in the tube moduli, but there were severe effects in their compressive strengths. Further packaging cycles had rapidly decreasing effects on the tubes' strength.

The major technology challenge was stiffness, which was well above the 6 MSI requirement. As for the compressive strength (buckling limit), it should be noted that, even when there were large variations due to fabrication and folding, the minimum demonstrated capability more than exceeded the operating antenna structure load requirements. Figure 13 is a test setup for the reduced temperature mechanical testing, and Figure 14 is an example of modulus and strength test results. 


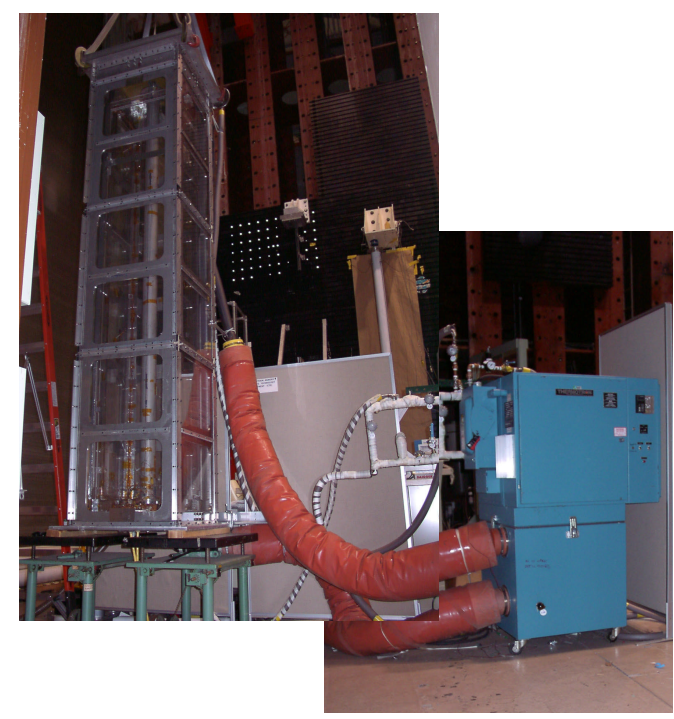

Fig. 13. ISAT Cryo-Mechanical Strut Test Facilities

\begin{tabular}{|c|c|c|c|}
\hline & $\begin{array}{c}\text { ISAT } \\
\text { Baseline }\end{array}$ & ILC Dover & L'Garde \\
\hline $\begin{array}{c}\text { Deployed } \\
\text { length } \\
\text { precision, mil. } \\
\text { as manufactured } \\
\text { stowed/deploye } \\
\text { d }\end{array}$ & $\begin{array}{c}< \pm 3.0 \\
< \pm 3.0\end{array}$ & Met & Met \\
\hline $\begin{array}{c}\text { Axial stiffness, } \\
\text { msi. - tensile/ } \\
\text { compressive }\end{array}$ & $>6.0 /$ & Met & Met \\
\hline $\begin{array}{c}\text { Bending } \\
\text { Stiffness, msi. }\end{array}$ & $>3.0$ & Met & Met \\
\hline $\begin{array}{c}\text { Buckling failure } \\
\text { load, lb. }\end{array}$ & $>35$ & Met & Met \\
\hline $\begin{array}{c}1^{\text {st }} \text { natural } \\
\text { frequency, Hz; } \\
\text { 0.001-g boost }\end{array}$ & .05 & $\begin{array}{c}\text { Met } \\
\text { w/special } \\
\text { provisions }\end{array}$ & Met \\
\hline $\begin{array}{c}\text { C.T.E., ppm / C } \\
\text { Under } \\
\text { invest- } \\
\text { igation }\end{array}$ & 0.1 & $\begin{array}{c}\text { Under } \\
\text { invest- } \\
\text { igation }\end{array}$ \\
\hline
\end{tabular}

Fig. 14. Example of Test Results

\section{Structural System Performance Simulation}

This task developed high-fidelity, specialized structural analytical simulation capabilities in order to project full-scale antenna orbital performance.

\section{Structural Performance Design Tool}

To conduct detailed structural/dynamics simulations, a new parametric analysis tool was created specifically for the ISAT-type RI antenna truss support structures. This tool, dubbed the Wright Finite Element Method (WFEM), was an easily extensible research-oriented finite element code that was simple to use for structures with repeated modular bays. One of its most useful features was its handling of special self-contained, interchangeable finite element modules that could be readily assembled into models to match changing antenna structure designs. Such elements accounted for the effects of tube bending and joint stiffness; applied a wide variety of boundary conditions and constraints; and determined RMS error shapes driven by geometric imperfections in the structure and radar panels.

WFEM has correlated well with other more conventional but generic FEM codes, and will be one of the key analytical tools for future simulations of the ISAT antenna structural/dynamic performance. Future improvements in the code will include expanding the current radar panel error analysis to include the effects of higher order surface errors on the antenna's RF signal performance. The tool's current features are shown in Figures 15.

\begin{tabular}{|l|}
\hline $\begin{array}{l}\text { Written specifically for repeated space truss } \\
\text { structures }\end{array}$ \\
\hline Static and modal analysis \\
\hline Forced dynamic response \\
\hline $\begin{array}{l}\text { Truss/panel tolerancing analysis (Monte Carlo } \\
\text { analysis), multiple error distribution types }\end{array}$ \\
\hline $\begin{array}{l}\text { Programmable modules, parametric, scriptable } \\
\text { code (number of bays, extrusion, scaling, non- } \\
\text { linear properties) }\end{array}$ \\
\hline Control and sensor elements \\
\hline Code validated with MSC/Nastran \\
\hline
\end{tabular}

Fig. 15. ISAT WFEM Analysis Tool Capabilities

Figure 16 illustrates the current antenna aperture panel shape error analysis WFEM module. It has the capacity to play an important part in the analytical prediction of the overall RF radar electrical performance.

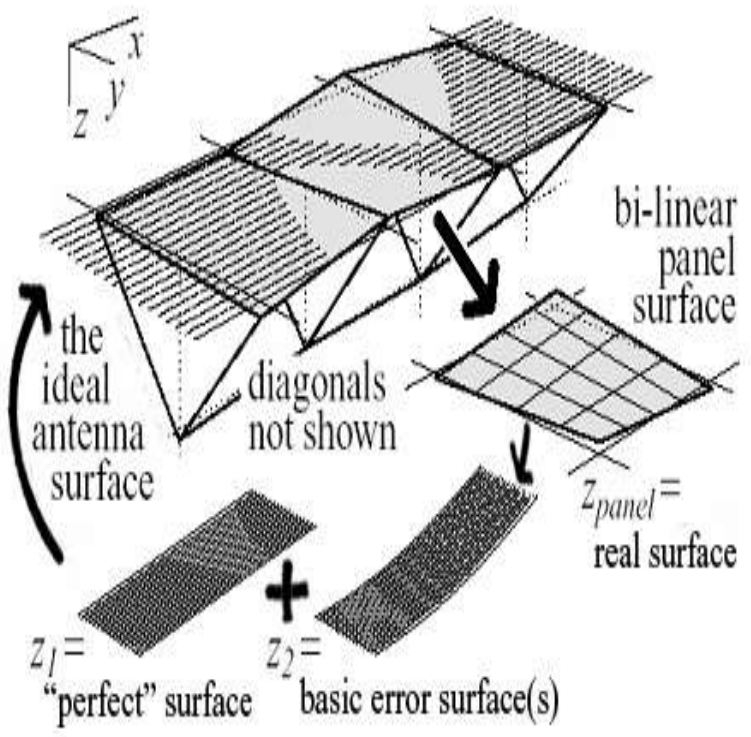

Fig. 16. ISAT Truss/Panel Deformations 


\section{Aperture Distortion Error Shape Analysis}

This statistical analysis capability was developed to account for random and repeated systematic errors in the truss structure. ${ }^{17}$ A Monte Carlo analysis ${ }^{18}$ was developed to guide the specification of hardware fabrication tolerances for truss element length variations. Member component length errors ${ }^{19}$ arose from a combination of fabrication imperfections, nonuniform mechanical and thermal properties, assembly and joint misalignment errors, and environmental effects.

Another objective of this work was to develop a reduced degree-of-freedom model to assess electronic and/or active mechanical antenna control needs and benefits. In particular, a method was devised using a polynomial surface rather than a flat plane to achieve best-fit antenna shape. The specialized surface functions reduced the number of degrees-of-freedom to simplify the development of an active-control algorithm. Figure 17 is an example of characteristic types of truss deformations.

\section{perfect shape (exactly planar antenna surface)}

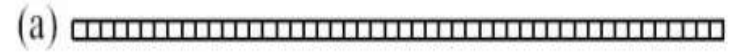

\section{errors of low spatial frequency}

(b)

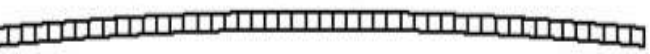

(c)

)

errors of high spatial frequency

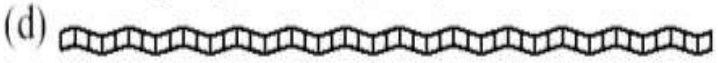

(e) $\square$

(f) (1)

Fig. 17. ISAT Representative Structures Manufacturing Distortion Patterns

Independent of the source, it was found that random errors in the truss members tended to cancel out, to some degree, but systematic errors tended to be additive. As a example, it was estimated that random statistical variations of $2 \mathrm{~mm}$ rms, commensurate with high quality manufacturing, produced best-fit aperture global errors on the order of millimeters.

\section{Risk Assessment}

A global risk assessment for new, immature technologies for specific applications required identifying and defining not only critical and enabling technologies, but key supporting technologies. Consequently, a three-tier system was selected that distinguished the critical, high risk, enabling technologies from the supporting and ground-based technologies. The assessment study addressed in detail the inflatable space-structures technologies for enabling a specific class of radar antennas. Tier 1 was based on these technology assessment results. Important supporting technologies were also identified, but not evaluated in great detail since their technology advancement was considered significantly lower risk than in Tier 1. To establish the TRL metrics the JPL ISAT Design Team, with support from their consultants, made the technology maturity estimates individually and in conference.

The risk of using new, immature technologies depends on both the TRL and the risk associated with advancing the technology from the time a "go" decision was made, to the time it was actually used. Technologyadvancement risk was a function of the (a) technical challenge associated with developing and validating technologies that were ground based, space-based, or both, (b) total development and validation cost, and (c) total available timeframe. Historically, sufficiently mature, reasonably funded technology advancements often have had major technical problems due to an overly restrictive schedule.

\section{Technology Maturity Matrix}

TRL's were based on technical task results: LRA Program; the ISAT Team, which draws its experience from JPL; Aerospace Corporation; NASA LaRC; and high-technology industry - notably L'Garde, Inc. and ILC Dover, Inc.

Tier 1 (Figure 18) critical and enabling technologies were sufficiently mature to ensure concept feasibility. Technology development was underway and functional demonstrations and validations were well defined. The risk for advancing these technologies to the point of application readiness ranges from high to moderate, depending on the specific technology element. The highest risk technology element to develop, which was considered very high, was characterizing the orbital, experimental rigidization of inflatable structural elements. Other technology elements were considered lower development risk.

Secondary and supporting technology elements (Figure 18), specified by Tier 2, represent wide-ranging concept maturity levels. The challenge associated with their technology advancement, however, was generally considered significantly lower risk than for Tier 1 . Since many of these technologies depended on specific application requirements, additional supporting technology elements would be identified as the system matured.

Tier 3 ground-based supporting technologies (Figure 18) also had a wide range of technology maturity levels. Many of them had low to very low development risks. But some, such as techniques for ground-based functional performance demonstrations for very large inflatable structures would present a major challenge, depending on specific objectives. 


\begin{tabular}{|c|c|c|c|c|c|}
\hline Specific Technologies & $\begin{array}{l}\text { Current } \\
\text { TRL }\end{array}$ & $\begin{array}{c}\text { Technology } \\
\text { Adv/Risk/Cost }\end{array}$ & Specific Technologies & $\begin{array}{l}\text { Current } \\
\text { TRL }\end{array}$ & $\begin{array}{c}\text { Technology } \\
\text { Adv/Risk } \\
\text { /Cost }\end{array}$ \\
\hline \multicolumn{3}{|c|}{ Tier One } & \multicolumn{3}{|l|}{ Tier Two } \\
\hline \multicolumn{3}{|c|}{ Material rigidization concepts: } & \multicolumn{3}{|l|}{ Secondary supporting techniques } \\
\hline Space radiation durability & $3-4$ & $\mathrm{~L}$ & $\begin{array}{l}\text { Materials orbital rigidization } \\
\text { implémentation techniques }\end{array}$ & 2 & $\mathrm{~L} / \mathrm{M}$ \\
\hline $\begin{array}{l}\text { Mechanical constitutive } \\
\text { properties dataset }\end{array}$ & 3 & $\mathrm{~L}$ & Launch restraint/release techniques & $2-3$ & $\mathrm{~L}$ \\
\hline $\begin{array}{l}\text { Inflatable structures folding } \\
\text { capability }\end{array}$ & $3-4$ & $\mathrm{~L} / \mathrm{H}$ & Ascent venting techniques & $2-3$ & $\mathrm{~L}$ \\
\hline $\begin{array}{l}\text { Rigidized structures element } \\
\text { stiffness/strength }\end{array}$ & $4-5$ & $\mathrm{~L}$ & On-orbit inflation/sensing/control & $2-3$ & $\mathrm{~L}$ \\
\hline Outgassing & $4-5$ & $\mathrm{~L}$ & $\begin{array}{l}\text { Design \& truss cables/battens/diagonals } \\
\text { fabrication capability }\end{array}$ & & $\mathrm{L}$ \\
\hline Long-term dimensional stability & $1 / 2$ & $\mathrm{~L}$ & $\begin{array}{l}\text { Rigidization structures manufacturing } \\
\text { capability }\end{array}$ & $2-3$ & M \\
\hline \multirow[t]{2}{*}{ Manufacturability } & 3 & $\mathrm{M} / \mathrm{H}$ & Non-inflatable structures development & $2-3$ & $\mathrm{~L}$ \\
\hline & & & Thermal control materials & $2-3$ & $\mathrm{~L}$ \\
\hline \multicolumn{6}{|c|}{ Truss structure system concept definition: } \\
\hline ISAT functional configuration & 4 & $\mathrm{~L}$ & \multicolumn{3}{|c|}{ Tier Three } \\
\hline Optimized structural system & $4-5$ & $\mathrm{~L}$ & Ground based supporting technologies & & \\
\hline $\begin{array}{l}\text { Mechanical packaging } \\
\text { techniques }\end{array}$ & $2-3$ & $\mathrm{M}$ & $\begin{array}{l}\text { Flexible materials handling processing } \\
\text { manufacturing }\end{array}$ & $3-4$ & $\mathrm{~L}$ \\
\hline $\begin{array}{l}\text { Deployment control } \\
\text { approaches/techniques }\end{array}$ & $2-3$ & $\mathrm{~L} / \mathrm{M}$ & $\begin{array}{l}\text { Highly specialized materials parts } \\
\text { element availability }\end{array}$ & $3-4$ & $\mathrm{~L}$ \\
\hline Panel/alignment precision & 3 & $\mathrm{~L}$ & $\begin{array}{l}\text { Manufacturing quality validation of } \\
\text { flexible material parts }\end{array}$ & $3-4$ & $\mathrm{~L}$ \\
\hline \multirow[t]{2}{*}{ Thermal/mechanical stability } & 2 & $\mathrm{~L}$ & $\begin{array}{l}\text { Precision assembly of large flexible } \\
\text { structures }\end{array}$ & & \\
\hline & & & $\begin{array}{l}\text { Subsystem mechanical performance } \\
\text { validation }\end{array}$ & & \\
\hline $\begin{array}{l}\text { Truss structural system } \\
\text { performance prediction: }\end{array}$ & & & $\begin{array}{l}\text { Functional subsystem system integration } \\
\text { techniques }\end{array}$ & & \\
\hline Structural system stiffness & 4 & $\mathrm{~L}$ & & & \\
\hline $\begin{array}{l}\text { Structural system dynamic } \\
\text { characteristics }\end{array}$ & $2-3$ & $\mathrm{~L}$ & & & \\
\hline $\begin{array}{l}\text { Structural system thermal } \\
\text { stability }\end{array}$ & 3 & $\mathrm{~L}$ & & & \\
\hline $\begin{array}{l}\text { Estimates of aperture mounting } \\
\text { precision/align. }\end{array}$ & 2 & $\mathrm{M} / \mathrm{H}$ & & & \\
\hline $\begin{array}{l}\text { Structural element deployment } \\
\text { simulation }\end{array}$ & 1 & $\mathrm{M} / \mathrm{H}$ & & & \\
\hline
\end{tabular}

Fig. 18. Risk Assessment Technology Maturity Matrix

\section{ISAT Conclusions}

This program clearly showed the high potential of contemporary RI technologies for meeting all the important ISAT mechanical mission requirements. However, there was need for additional risk reduction bring the enabling technologies to a moderate TRL and the supporting technologies to a low TRL.

Important results from both RI technology programs:

- The generated structures tube test dataset resulted in an excellent definition of the effects of constitutive relationships on mechanical performance.

- High-efficiency mechanical packaging of flexible members usually caused some damage to the matrix and/or fibers. However, when it was accounted for in the structural design, damage was not a serious problem, but does warrant future examination.

- RI member mechanical performance was very sensitive to the quality of fabrication.

- Several supporting technologies were at a low TRL; however, the risk of advancing them was not high.
- Overall technology risk cannot be lower than the highest tall-pole technology risk.

- Risk associated with advancing key technologies to flight readiness depended on (a) allowable schedule, (b) magnitude of the challenge, and (c) required "validation", i.e. ground-based or on-orbit.

- LRA and ISAT Programs both made significant technology maturity advances.

- Ground-test limitations of the RI deployment process requires orbital demonstration to establish initial space-deployed geometric precision.

\section{Rigidizable Inflatable Structures Technology}

\section{Summary}

Fifty years of interest in the technology of RI space structures led to the advent of the IAE orbital demonstration. Its flight performance encouraged serious evaluation of RI support structures for specific classes of space applications, in particular, the LRA. The structural characterization and technology 
advancement during the LRA Program provided a database that significantly contributed to the creation of DARPA/SPO's ISAT Program. This ongoing program is addressing the development of an orbital flight demonstration system to test electrical and mechanical performance in the 2010 timeframe.

\section{ACKNOWLEDGEMENTS}

The research described in this paper was carried out at the Jet Propulsion Laboratory, California Institute of Technology, under the sponsorship of the Defense Advanced Research Projects Agency.

The authors would like to acknowledge significant contributions made to the LRA Program by Chris Moore previously of NASA Langley Research Center and currently at NASA Headquarters. He is a principal and founding member of the original LRA government team. His efforts and expertise led to designing and implementing a unique LaRC test facility for the characterization of RI structural elements which were crucial to assessing these technologies for space applications.

\section{REFERENCES}

1. Freeland, R. E. and Bilyeu, G., IN-STEP Inflatable Antenna Experiment, IAF Paper 92-0301, presented at the $43^{\text {rd }}$ Congress of the International Astronautical Federation, Washington, D.C., Aug. 28-Sept. 5, 1992.

2. Freeland, R. E., Bilyeu, G., and Veal, G. R., "Validation of a Unique Concept for a Low-Cost, Lightweight Space Deployable Antenna Structure," IAF Paper 93-I.1.204, presented at 44th Congress of the International Astronautical Federation, Graz, Austria, Oct. 16, 1993.

3. Satter, C. M. and Freeland, R. E., "Inflatable Structures Technology Applications and Requirements," AIAA Paper 95-3737, presented at the Space Programs and Technical Conference, Huntsville, AL, Sept. 26-28, 1995.

4. Freeland, R. E., Bilyeu, G.D., Veal, G. R., "Development of Flight Hardware for a Large, Inflatable-Deployable Antenna Experiment," IAF Paper 95-1, 5.0.1, presented at 46th Congress of International Astronautical Federation, Oslo, Norway, Oct. 2-6, 1995.

5. Freeland, R. E., Bilyeu, G. D., and Veal, G. R., "Large Inflatable Deployable Antenna Flight Experiment Results," IAF Paper 971.3.01, presented at the 48th Congress of the International Astronautical Federation, Turin, Italy, Oct. 6-10, 1997.

6. Freeland, R. E. and Veal, G. R., "Significance of the Inflatable Antenna Experiment Technology" presented at the 39th AIAA/ASME/ASCE/AHS/ASC Structures, Structural Dynamics and Materials Conference, AIAA/ASME/AHS Adaptive Structures Forum, Long Beach, CA, April 20-23, 1998.

7. Freeland, R. E., Bilyeu, G. D., Veal, G. R., and Mikulas, M.M., "Inflatable Deployable Space Structures Technology Summary," IAF-98-I.5.01 presented at 49th Congress of the International Astronautical Federation, Melbourne, Australia, Sept. 28-Oct. 2, 1998.

8. Greschik, G., Mikulas, M. M., and Freeland, R. E. "The nodal concept of deployment and the scale model testing of its application to a membrane antenna," in The 40th AIAA/ASME/ASCE/AHS/ ASC Structures, Structural Dynamics, and Materials Conference and AIAA/ASME Adaptive Structures Forum, volume 4, pages 25462554, St. Louis, MO, Apr. 12-15 1999. AIAA-99-1523-CP.

9. Greschik, G., Mikulas, M. M., and Freeland, R. E. "Scale model testing of nonlinear phenomena with emphasis on thin film deployable structures," In S. Pellegrino and S. D. Guest, editors, IUTAM-IASS Symposium on Deployable Structures: Theory and Applications. Proceedings of the IUTAM Symposium held in Cambridge, UK, Sept. 6-9, 1998, volume 80 of Solid Mechanics and its Applications, pages 127-136, Boston, MA. Kluwer Academic Publishers, 2000.

10. Thomson, M. W. "The AstroMesh Deployable Reflector." Proceedings of 5th International Satellite Conference, (IMSC '97), Pasadena, CA, Jun. 16-18, 1997, JPL Pub. 97-11, pgs. 393-398.

11. Greschik, G., Mikulas, M. M., and Freeland, R. E. and Helms, R. G. "A New Structural Concept (Tension Drum) for Providing High Accuracy in Large Stretched Membrane and Mesh Reflectors." CIT/JPL Document JPL D-19821, Dec. 6, 1999 (Limited Access).

12. Stuckey, W., Steckel, G., Meshishnek, M., and Coleman, D. "Space Environment Simulation Testing of Inflatable Rigidized Materials." Mar. 31, 2004, Aerospace Report No. TOR-2004(3000)-6.

13. Mankins, John C. "Approaches to strategic research and technology (R\&T) analysis and road mapping." International Astronautical Federation Paper 01-U202, Oct. 2001

14. Steckel, G., and Stuckey, W. "Mechanical and Thermal Properties of Rigidizable/inflatable Materials from ILC Dover." Aerospace Report No. ATR-2003(7894)-2, Sept. 25, 2003. (Limited Access)

15. G. Steckel and W. Stuckey. Mechanical and Thermal Properties of Rigidizable/Inflatable Materials from L'Garde, Inc. Aerospace Report to be issued.

16. Scarborough, S., Cadogan, D., Pederson, L., Blandino, J., Steckel, G., Stuckey, W. "Elevated Temperature Mechanical Characterization of Isogrid Booms." 44th AIAA/ASME/ASCE/AHS Structures, Structural Dynamics, and Materials Conference, Norfolk, VA, April 7-10, 2003. AIAA-2003-1824

17. Hedgepeth, J. M. "Influence of fabrication tolerances on the surface accuracy of large antenna structures." AIAA Journal, 20(5):680 686, May 1982. AIAA 82-4116.

18. Greschik, G., Mikulas, M. M., Helms, R. G., Freeland, R. E. "Strip Antenna Figure Errors Due to Support Truss Member Length Imperfections." Presented at 45th Structures, Structural Dynamics, Materials Conference, 12th Adaptive Structures Conf., 6th AIAA Non-Deterministic Approaches Forum, 5th Gossamer Spacecraft Forum. Palm Springs, CA, Apr. 19, 2004. AIAA-2004-1601.

19. Greene, W. H. "Effects of Random Member Length Errors on the Accuracy and Internal Loads of Truss Antennas." Journal of Spacecraft, 22(5):554-559, Sept.-Oct. 1985. AIAA 82-4116 